\title{
Word-Finding Strategies in Closed Head Injured Adults
}

\author{
Juleen Kleiman, BA (Speech and Hearing Therapy) (Witwatersrand) \\ Lesley Bucke, BA (Speech and Hearing Therapy) (Witwatersrand) \\ Department of Speech Pathology and Audiology, \\ University of Witwatersrand, Johannesburg
}

\begin{abstract}
Word-finding difficulties are a common and prominent language deficit following closed head injury. The word-finding difficulties of three closed head injured patients were investigated within the framework of compensatory strategies using Teicher's Taxonomy of WordFinding Strategies /Teicher, 1986/. The word-finding difficulties were evaluated during procedural discourse and two confrontation naming conditions. Each subject's communicative competence and language ability was determined. Results indicated that all subjects employed a wide range of strategies, particularly during confrontation naming, but with differential effectiveness. A relationship was noted between the strategy's effectiveness and the subject's pragmatic ability. The results are discussed in the light of the existing literature on head injury. The theoretical and clinical implications are considered.
\end{abstract}

\section{OPSOMMING}

Woordvindprobleme is ' $n$ algemene en prominente taalverskynsel na geslote hoofbeserings. Woordvindprobleme van proefpersone met geslote hoofbeserings is geëvalueer binne' $n$ raamwerk van kompensasiestrategieë deur gebruik te maak van Teicher se "Taxonomy of Word-Finding Strategies" (Teicher, 1986). Die woordvindprobleme is geëvalueer tydens proseduregesprekke en twee konfrontasiebenoemingstake. Elke proefpersoon se kommunikasie. en taalvaardigheid is bepaal. Die resultate dui daarop dat al die proefpersone gebruik gemaak het van ' $n$ wye reeks stategieë, veral tydens konfrontasiebenoeming, maar met variasie in effektiwiteit. 'n Ooreenkoms is opgemerk tussen die strategieë wat gebruik is en die proefpersone se pragmatiese vermoëns. Die resultate is bespreek in die lig van reeds bestaande literatuur in verband met geslote hoofbeserings en daar is verwys na teoretiese en kliniese implikasies.

Closed Head Injury $(\mathrm{CHI})$ has been termed "the invisible epidemic" (Holland, 1982) in view of the marked increase in the incidence of the disorder during this decade (Annegers, Grabouw, Kurland and Laws, 1980). The primary source of pathophysiology in $\mathrm{CHI}$ is that of blunt trauma to the skull which results in multiple diffuse damage to the brain. Discontinuation of neural substance and shearing and straining of the axons in the white brain matter occurs (Hagen, 1984). This results in a diversity of cognitive, memory and language deficits, based on the combination of pathophysiologic mechanișms and severity of the injury (Ylivisaker and Szekeres, 1986). The CHI patient therefore presents the speech-language pathologist with a "unique and complex diagnostic, prognostic and treatment challenge" (Hagen, 1984:245).

The neurobehavioural and linguistic sequelae following CHI constitutes an area of much controversy. Different labels including "aphasia" (Luria, 1970), "subclinical aphasia" (Sarno, 1980) and "confused" language (Hagen, 1984) have been adopted to describe the linguistic symptoms following CHI. The heterogeneity of this population is being increasingly well recognised. Despite this heterogeneity, researchers are in agreement that anomia is a common and prominent language deficit following $\mathrm{CHI}$ (Hagen, 1984; Heilman, Safron and Geschwind, 1971; Levin, Benton and Grossman, 1981).

Anomia has been defined as poor access to lexical items (word retrieval) and as a failure to name on confrontation and during discourse /Goodglass, Kaplan, Weintraub and
Ackerman, 1976). The primary cortical areas identified as being responsible for naming abilities include the parietotemporo-occipital areas of the left dominant hemisphere (Luria, 1975; Benson, 1979). The CHI patient frequently presents with circumlocutions, paraphasias and reduced fluency which are typical of aphasia (Holland, 1982). In addition, CHI patients reportedly exhibit "non-aphasic" naming errors resulting from their impulsivity, perceptual disinhibition and lack of language boundness (Holland, 1982; Teicher, 1986).

Within the past few years there has been a renewed focus on the importance of observing and assessing language and behaviour of the $\mathrm{CHI}$ within a compensatory strategy framework (Kirchner and Skarakis-Doyle, 1983; Penn, 1985; Penn and Cleary, 1987; Teicher, 1986). When compensation follows a head injury we are observing the patient's direct attempt to compensate for his primary deficits. This is in accord with Piaget's (1952) belief that the human organism constantly strives to maintain a balance and adapt to environmental demands. This process of equilibrium is determined in part by neurological and subject variables, and in part by ecologic variables (Penn and Cleary, 1987).

Compensatory strategies, which may develop spontaneously or which may be trained, have been defined as alternate methods of controlling and manipulating information (Kirchner and Skarakis-Doyle, 1983). The individual adopts these strategies to meet the communicative demands of the situation when he is unable to bring together all the necessary resources, as a result of brain damage [Penn, 
1985). The degree to which a brain damaged patient will develop and utilise compensatory strategies will play a major role in determining the eventual outcome for the patient (Penn, 1985). Teicher (1986) examined the word-finding strategies employed by a group of $\mathrm{CHI}$ individuals during an instance of word-finding difficulty. The results revealed that by utilising a behavioural taxonomy to assess word-finding strategies, many of the strategies employed by the subjects could be identified, described and compared within and across subjects. Profiles of successful and unsuccessful strategies and their pragmatic effectiveness were identified. Furthermore, the importance of evaluating naming ability during discourse, as well as confrontation naming was stressed. This study highlighted the potential value of the $\mathrm{CHI}$ population's word-finding difficulties within a compensatory framework. According to Ylvisaker and Szekeres (1986:474) "Impaired social interaction is often the residual deficit most troubling for the patient's family and for the patient himself." Assessment tools which therefore have as their basis a social interaction model of communication which incorporates linguistic, pragmatic, social and cognitive variables are invaluable (Penn and Cleary, 1987).

The purpose of this study therefore is to examine the wordfinding compensatory strategies being employed by three $\mathrm{CHI}$ subjects during discourse and confrontation naming and to determine the effectiveness of these strategies in communicative interaction. By evaluating $\mathrm{CHI}$ wordfinding difficulties in terms of compensatory strategies a pattern of behaviour may emerge which may offer insight into the central nervous sytem (Marshall, 1976) as well as provide us with useful prognostic and diagnostic information. This will then assist us in designing more effective therapeutic strategies as the ultimate therapeutic goal, according to Penn $\{1985\}$, is to teach positive strategies which will increase pragmatic competence and flexibility of style.

\section{METHOD}

\section{Aims}

The aim of the present study was to identify, describe and compare the word-finding strategies employed by three $\mathrm{CHI}$ subjects during procedural discourse and confrontation naming tasks in an effort to adapt to their word-finding difficulties. The study was further designed to determine whether a relationship exists between the nature and the effectiveness of such strategies, and the individual's overall communicative effectiveness and language ability.

\section{Subjects (Ss)}

Three English speaking subjects who had sustained closed head injuries as a result of motor vehicle accidents $\mid$ Ss 1 and 2) and assault (S3) were selected as subjects for this study. Ss 1 and 3 were males, S2 female and their age range was 27.1 years to 44.4 years (mean 33.3 years). Mean coma duration of the subjects was 4 weeks (range $2-6$ weeks), thus indicating a severe head injury according to the criteria suggested by Russell (1971). All subjects were neurologically stable at the time of testing with a mean post-injury time of 21 months (range $8-48$ months). Subjects were all pretrauma. tically right-handed and had completed at least 11 years of schooling. Family reports indicated that subjects were of average intellectual capacity prior to the accident. No previous history of sensory or motor deficit was reported nor was any history of drug or alcohol abuse noted. Hearing was within normal limits for all three subjects at the time of testing. Further relevant clinical and biographical details are included in table 1 below.

\section{Testing material}

As there are presently no language tests designed specifically for the CHI population it was necessary to employ and

Table 1: Relevant clinical and biographical detail for all subjects

\begin{tabular}{|c|c|c|c|}
\hline & SUBJECT 1 & SUBJECT 2 & SUBJECT 3 \\
\hline Age & 27.1 years & 28.3 years & 44.4 years \\
\hline Sex & Male & Female & Male \\
\hline Educational & $\begin{array}{l}\text { Standard } 9 \\
\text { Apprentice } \\
\text { Matric }\end{array}$ & $\begin{array}{l}\text { Diploma Greenoaks } \\
\text { Secretarial College }\end{array}$ & Standard 8 \\
\hline Premorbid laterality & Right & Right & Right \\
\hline Coma (weeks) & 3 & 6 & 2 \\
\hline $\begin{array}{l}\text { Time since injury to testing } \\
\text { (months) }\end{array}$ & 48 & 8 & thes \\
\hline History of speech therapy & Yes, until 1984 & Presently receiving theraphy & Yes, until 1987 \\
\hline Present motor problems & L-arm hemiplegia & $\begin{array}{l}\text { L-hemiplegia. } \\
\text { Previous L-side neglect } \\
\text { resolved }\end{array}$ & L-hemiplegia \\
\hline Occupation & $\begin{array}{l}\text { Supervising packing of } \\
\text { medical supplies }\end{array}$ & Unemployed & Unemployed \\
\hline $\begin{array}{l}\text { Immediate post-trauma cat } \\
\text { scan results }\end{array}$ & $\begin{array}{l}\text { Diffuse cerebral oedema } \\
\text { with small parieto-temporal } \\
\text { haemorrhage on left }\end{array}$ & $\begin{array}{l}\text { Diffuse cerebral oedema } \\
\text { with parieto-occipital } \\
\text { haemorrhage on right }\end{array}$ & $\begin{array}{l}\text { Intracerebral haemorrhage } \\
\text { occupying most of right tem- } \\
\text { poral lobe with right and left } \\
\text { lateral ventricle involve- } \\
\text { ment. Craniotomy to drain } \\
\text { sub-dural haemotoma }\end{array}$ \\
\hline
\end{tabular}


modify tests designed for other neurogenic groups such as aphasia. The following tests were administered:

a. Western Aphasia Battery (WAB) (Kertesz, 1980) - the Aphasia Quotient (AQ) was only administered as it serves as a functional measure of spoken language impairment. It thus provided an overall language severity score in subjects and a basis for comparison between subjects.

b. Prutting's Pragmatic Protocol (Prutting, 1982) - a strong relationship seems to exist between the CHI Ss' effective use of compensatory strategies and their overall communicative competence (Cleary, 1985; Teicher, 1986). The general pragmatic communication abilities of the Ss were therefore assessed using Prutting's Pragmatic Protocol \{Prutting, 1982\}. This provides a global measure of communicative competence and places language in the context of socialisation.

The data for the analysis consisted of a 10 minute interactional language sample which was simultaneously video- and audiotaped. Topics discussed in this sequence were: family structure, the subject's accident, daily activities and interests.

c. Discourse Tasks - this is a procedure for sampling and quantifying connective speech for $\mathrm{CHI}$ Ss who display social and vocational communicative deficits yet have difficulty on standardised aphasia tests (Milton, Prutting and Binder, 1984). Procedural discourse was employed as the mode of elicitation and it provides the tester with a moderate level of context control and has temporal constraints (Ulatowska, North and Macaluso-Haynes, 1981). The task involved a complete discussion of three daily activities noted for their familiarity and relatively high frequency of occurrence for an adult (Ulatowska et al. 1981). Instructions given were: "I'd like you to tell me as completely as possible, how to make a sandwich; change a bed; wash laundry."

d. Confrontation naming tests - chosen to evaluate different aspects of confrontation naming. The Boston Naming Test (BNT) (Kaplan, Goodglass and Weintraub, 1976) was employed to evaluate object \{noun\} naming on confrontation, while the Action Naming Test (ANT) (Obler and Albert, 1986) was employed to evaluate action (verb) naming on confrontation. Repetition and cueing were provided if the subject did not respond after a 20 second delay.

Behaviours associated with word-finding difficulties on the procedural discourse tasks, the BNT and the ANT, were described using Teicher's Behavioural Taxonomy of Word-Finding Strategies (Teicher, 1986), based on Penn's Taxonomy of Compensatory Strategies (1985). This qualitative analysis yields pertinent information about language use difficulties in CHI. Five broad strategy categories were derived and are displayed in table 2 . An additional category for analysis "Repetition" was in. cluded in the taxonomy as Penn (1985) makes use of this strategy in her Taxonomy of Compensatory Strategies. Repetition facilitates, processing and captures the listener's attention. A detailed description and example of each word-finding strategy is displayed in appendix I.
Table 2: Teicher's taxonomy of word-finding strategies (Teicher, 1985)

\begin{tabular}{|l|l|}
\hline Elaboration & Fluency \\
Description & Silent pause \\
Noncumlocution & Filled pause \\
Symbolic Noise & Social \\
Meaningless Gesture & Comment Clause \\
Iconic/Pantomime & Self-correction \\
Facial Expression & Requests Help \\
Deictic & Other \\
& $\begin{array}{l}\text { Any behaviour not includ- } \\
\text { ed in the preceding catego- } \\
\text { ries }\end{array}$ \\
\hline
\end{tabular}

Testing procedure

Testing was carried out individually and extended over a number of morning sessions in an attempt to eliminate fatigue as a confounding variable. In order to reduce anxiety, rapport was established with each subject prior to his being tested.

Analysis of data

Standardised tests administered were scored according to the procedure laid down in the test manual. Non-standardised test results were analysed according to the methods described previously.

The examiner and two reliability judges completed Prutting's Pragmatic Protocol (Prutting, 1982) independently in order to measure reliability. Point-to-point inter-rater reliability was calculated separately for the three categories of the protocol. Reliability was $82 \%$, with a range extending from $75,5 \%$ to $85,5 \%$. Rating was thus reliable, based on Silverman's (1977:157) minimal acceptable inter-rater reliability of 0,75 .

Three raters rated each $\mathrm{Ss}^{t}$ word-finding strategies using Teicher's Taxonomy of Word-Finding Strategies (Teicher, 1986). The raters involved one of the authors and two third year speech therapy students blind to the aims of the study. All raters had been trained in the use of the profile. Training sessions included familiarisation, discussion and explanation of each strategy listed on the taxonomy. Clinical videotapes of CHI Ss engaged in conversation were chosen to illustrate and clarify certain strategies. Judges rated each interaction separately and independently on all three viewings and completed the ratings according to their observation of relevant dimensions.

During the first viewing, raters were required to underline when a word-finding difficulty had occurred. During the second viewing, the raters were required to comment if the word search was successful or unsuccessful. A successful word search was any attempt at word-finding which resulted in the production of a specific lexical item. In an unsuccessful word search, the listener may not have known the desired word, but knew when the speaker had not reached the target word or when the search strategy was ineffective 
(Teicher, 1986). Finally, the raters were required to categorise the behaviours accompanying the word-finding instances into Teicher's Behavioural Taxonomy (Teicher, 1986).

Point to point inter-rater reliability was determined. Reliability values ranged from $83.2 \%$ for $\mathrm{S} 2$ to $77.4 \%$ for S1. It can therefore be concluded that rating was reliable according to Silverman's $\{1977 ; 157\}$ minimal acceptable interrater reliability value of 0.75 .

Duration of each word search for all Ss was analysed quantitatively by computing the overall ratings of successful and unsuccessful searches.

It was calculated from the moment of onset of the search to the moment of successful or unsuccessful achievement and then rounded to the nearest half second. Finally, the percentage of time each initial word-finding strategy and strategy sequence was employed successfully and unsuccessfully was computed for each subject.

\section{RESULTS AND DISCUSSION}

\section{a. Westem Aphasia Battery (Kertesz, 1980)}

Subject 1 obtained a WAB Aphasia Quotient of 74.8 while Ss 2 and 3 scored 92.6 and 64.0 respectively. None of the Ss therefore scored above 93.8 which is the suggested cut-off point for aphasia (Kertesz, 1980). This indicates an element of language form disturbance for all Ss, the nature of which was diffuse. This contradicts Milton, Prutting and Binder's (1984) opinion that CHI Ss do not present with a degree of aphasia. Word-finding difficulties were observed in all Ss in addition to problems in the areas of comprehension and repetition which correlates with Cleary's (1985) findings. Brooks (1984), Cleary (1985) and Groher (1977) have suggested that an underlying memory problem together with reduced attention and concentration span are contributory factors towards overall difficulties in these areas. Naming ability and verbal associative fluency have been shown to be the most effective predictors of injury (Levin et al. 1981) which corresponds with the findings. S3 presented with the most severe generalised cerebral dysfunction in addition to the most severe linguistic deficit.

\section{b. Prutting's Pragmatic Protocol (Prutting, 1982)}

All 3 Ss presented with a greater or lesser degree of pragmatic difficulty. S2 experienced the least overall difficulty $\{15 \%$ inappropriate responses\}, S1 presented with $22 \%$ inappropriate responses while $\mathrm{S} 3$ experienced the most overall difficulty $(66 \%)$. Similar findings were found on the WAB \{Kertesz, 1980). This observation contributes towards Irvine and Behrmann's $\{1986)$ finding of a balance existing between language form and language use skills in $\mathrm{CHI}$ individuals.

Results indicate that overall appropriateness of subjects' responses occurred mainly in the Utterance Act and the Propositional Act categories while the least appropriate response occurred in the Ilocutionary/Perlocutionary Act. This is in agreement with Cleary (1985), Milton et al. (1984\}, and Teicher $(1986)$ and it seems to imply that $\mathrm{CHI}$ individuals function inadequately in their roles as discourse partners.

Table 3: Subjects' performance on the procedural discourse tasks

\begin{tabular}{|c|c|c|c|c|c|}
\hline Number of word-finding difficulties & & & 32 & 7 & 19 \\
\hline \multirow{2}{*}{ Percentage: } & \multicolumn{2}{|l|}{ Successful } & $69 \%$ & $86 \%$ & $74 \%$ \\
\hline & \multicolumn{2}{|l|}{ Unsuccessful } & $31 \%$ & $14 \%$ & $26 \%$ \\
\hline \multirow{2}{*}{ Duration: } & Successful & $\begin{array}{l}\text { Mean } \\
\text { Range } \\
\end{array}$ & $\begin{array}{l}2.0 \mathrm{sec} \\
0.5-5.0 \mathrm{sec}\end{array}$ & $\begin{array}{l}1.0 \mathrm{sec} \\
0.5-1.0 \mathrm{sec}\end{array}$ & $\begin{array}{l}2.0 \mathrm{sec} \\
1.0-5.0 \mathrm{sec}\end{array}$ \\
\hline & Unsuccessful & $\begin{array}{l}\text { Mean } \\
\text { Range } \\
\end{array}$ & $\begin{array}{l}3.5 \mathrm{sec} \\
0.5-7.0 \mathrm{sec}\end{array}$ & $2.0 \mathrm{sec}$ & $\begin{array}{l}4.0 \mathrm{sec} \\
2.0-5.0 \mathrm{sec}\end{array}$ \\
\hline \multirow{2}{*}{ Number of different strategies used: } & Successful & & 7 & 2 & 4 \\
\hline & Unsuccessful & & 7 & 2 & 4 \\
\hline \multirow{2}{*}{ Number of different strategy sequences: } & $\underline{\text { Successful }}$ & & 5 & 0 & 3 \\
\hline & Unsuccessful & & 6 & 1 & 2 \\
\hline \multirow{2}{*}{ Most frequently used initial strategy: } & Successful & & $\begin{array}{l}\text { Filled pause } \\
37 \%\end{array}$ & $\begin{array}{l}\text { Silent delay } \\
86 \%\end{array}$ & $\begin{array}{l}\text { Filled pause } \\
58 \%\end{array}$ \\
\hline & Unsuccessful & & $\begin{array}{l}\text { Filled pause } \\
30 \% \\
\text { Repetition } \\
30 \%\end{array}$ & $\begin{array}{l}\text { Silent delay } \\
100 \%\end{array}$ & $\begin{array}{l}\text { Filled pause } \\
100 \%\end{array}$ \\
\hline \multirow{2}{*}{ Most frequently used stategy sequence: } & Successful & & $\begin{array}{l}\text { Filled pausel } \\
\text { Repetition } \\
23 \%\end{array}$ & & $\begin{array}{l}\text { Filled pause } \\
\text { Silent delay } \\
21 \%\end{array}$ \\
\hline & Unsuccessful & & $\begin{array}{l}\text { Filled pause/ } \\
\text { Repetition } \\
20 \%\end{array}$ & & $\begin{array}{l}\text { Filled pause/ } \\
\text { Description } \\
60 \%\end{array}$ \\
\hline
\end{tabular}




\section{c. Procedural discourse tasks}

While all 3 subjects presented with word-finding difficulties they all experienced relatively high levels of success for production of the desired lexical item following this difficulty. Table 3 describes the subjects' performance during the procedural discourse tasks.

Both the duration mean and range of word searches were calculated. All Ss presented with a longer duration when strategies were unsuccessful. For example S3's mean duration of a successful word search was 2 seconds while that of an unsuccessful word search was 4 seconds, a difference of 2 seconds. A wide range of successful and unsuccessful initial word-finding strategies were employed, namely filled pause, silent delay and repetition, though a greater number and variation of strategies were used when success was not attained. This may relate to the Ss' attempts to compensate for increased instances of word-finding difficulty. Certain strategies occurred more frequently than others, particularly fluency strategies. Silent delay and filled pause were employed $69 \%$ of the time during a successful word search and $75 \%$ during an unsuccessful word search. Repetition was the most facilitative initial strategy and was employed by Ss to maintain listener attention (Penn, 1985). Ss 1 and 3 employed word-finding strategy sequences, successfully and unsuccessfully, in an attempt to produce desired lexical items. Filled pause was the most frequently used initial strategy in all sequences. Filled pause may be potentially distracting if used too often (Cleary, 1985). This was particularly evident in S1's speech where it was the most frequently used initial strategy and part of the most frequently used strategy sequence, both successfully and unsuccessfully. This may relate to the increased number of word-finding difficulties experienced by S1.

\section{d. Confrontation Naming Tests}

- Boston Naming Test (BNT) (Kaplan et al. 1976)

All Ss experienced word-finding difficulties and, as a result, employed word-finding strategies to overcome this difficulty.

Table 4 illustrates the Ss' performance on the BNT (Kaplan et al. 1976). The level of success for production of the desired lexical item was relatively low for all Ss $-16 \%, 20 \%$ and $42 \%$ for Ss 1,2 and 3 respectively. The duration mean and range of word searches indicates that all Ss presented with a longer duration when strategies were unsuccessful, for example 8 seconds versus 2 seconds for S3. The Ss' results differed from each other for successful and unsuccessful initial word-finding strategies. However, for all Ss, an increase in the number and variation of different initial strate. gies and word-finding strategy sequences was evident when success was unattainable. All Ss employed word-finding strategy sequences, but the most frequently used successful and unsuccessful strategy sequences varied across and within Ss. S2, however, employed the same successful and unsuccessful strategy sequences, silent delay/description. This is hypothesised to relate to S2's car eful self-monitoring. Elaboration strategies [description and elimination), fluency

Table 4: Subjects' performance on the BNT

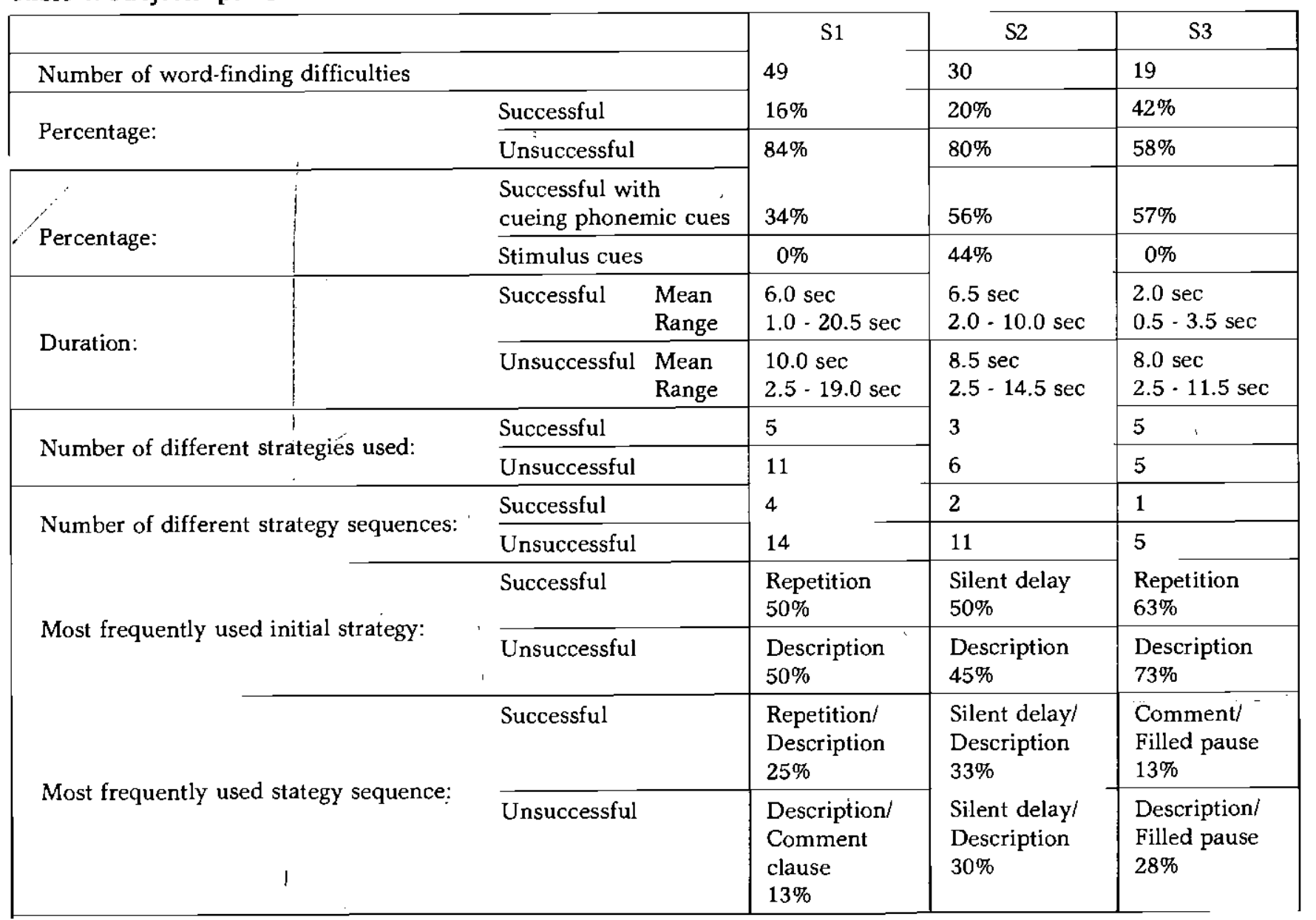


strategies (silent delay and filled pause) and social strategies (comment clause, self-correction and requests help) were the most frequently used initial strategies. All the Ss required cues following the failure to name the desired lexical item. Phonemic cues were the most successful in facilitating retrieval of the specific lexical item for all Ss.

- Action Naming Tests (ANT) (Obler and Albert, 1986)

All 3 Ss experienced instances of word-finding difficulty on the ANT. They employed word-finding strategies to overcome their difficulty. pragmatic behaviour and lack of self-monitoring. The most frequently used successful and unsuccessful strategy sequences varied across and within Ss except S2 who employed the same strategy sequence (silent delay - description) successfully and unsuccessfully: This was also evident on the BNT (Kaplan et al. 1976). Fluency and elaboration strategies were the most frequently employed initial word-finding strategies. All Ss required cues following the failure to name the desired word, and phonemic cues were the most successful in facilitating retrieval of the specific lexical item. The superiority of phonemic cues over stimulus and verbal contextual cues is confirmed by the results on

Table 5: Subjects' performance on the ANT

\begin{tabular}{|c|c|c|c|c|c|}
\hline & & & S1 & S2 & S3 \\
\hline \multicolumn{3}{|l|}{ Number of word-finding difficulties } & 22 & 18 & 17 \\
\hline \multirow{2}{*}{ Percentage: } & \multicolumn{2}{|l|}{$\underline{\text { Successful }}$} & $27 \%$ & $22 \%$ & $30 \%$ \\
\hline & \multicolumn{2}{|l|}{ Unsuccessful } & $73 \%$ & $78 \%$ & $70 \%$ \\
\hline \multirow{2}{*}{ Percentage: } & \multicolumn{2}{|c|}{$\begin{array}{l}\text { Successful with } \\
\text { cueing phonemic cues }\end{array}$} & $61 \%$ & $83 \%$ & $53 \%$ \\
\hline & \multicolumn{2}{|c|}{$\begin{array}{l}\text { Verbal contextual } \\
\text { cues }\end{array}$} & $45 \%$ & $56 \%$ & $29 \%$ \\
\hline \multirow{2}{*}{ Duration: } & Successful & $\begin{array}{l}\text { Mean } \\
\text { Range }\end{array}$ & $\begin{array}{l}5.0 \mathrm{sec} \\
2.0-8.0 \mathrm{sec}\end{array}$ & $\begin{array}{l}9.5 \mathrm{sec} \\
4.5-13.0 \mathrm{sec}\end{array}$ & $\begin{array}{l}3.0 \mathrm{sec} \\
1.5-5.0 \mathrm{sec}\end{array}$ \\
\hline & Unsuccessful & $\begin{array}{l}\text { Mean } \\
\text { Range }\end{array}$ & $\begin{array}{l}11.0 \mathrm{sec} \\
5.5-18.5 \mathrm{sec}\end{array}$ & $\begin{array}{l}10.0 \mathrm{sec} \\
4.5-18.0 \mathrm{sec}\end{array}$ & $\begin{array}{l}6.5 \mathrm{sec} \\
0.5-16.5 \mathrm{sec}\end{array}$ \\
\hline \multirow{2}{*}{ Number of different strategies used: } & $\underline{\text { Successful }}$ & & 4 & 3 & 3 \\
\hline & Unsuccessful & & 7 & 4 & 3 \\
\hline \multirow{2}{*}{ Number of different strategy sequences: } & Successful & & 3 & 2 & 0 \\
\hline & Unsuccessful & & 7 & 8 & 1 \\
\hline \multirow{2}{*}{ Most frequently used initial strategy: } & Successful & & $\begin{array}{l}\text { Filled pause } \\
38 \%\end{array}$ & $\begin{array}{l}\text { Description } \\
50 \%\end{array}$ & $\begin{array}{l}\text { Self-correct } \\
40 \% \\
\text { Filled pause } \\
40 \% \\
\end{array}$ \\
\hline & Unsuccessful & & $\begin{array}{l}\text { Silent delay } \\
38 \%\end{array}$ & $\begin{array}{l}\text { Description } \\
57 \%\end{array}$ & $\begin{array}{l}\text { Description } \\
50 \%\end{array}$ \\
\hline \multirow{2}{*}{ Most frequently used stategy sequence: } & Successful & & $\begin{array}{l}\text { Repetition/ } \\
\text { Pantomime } \\
33 \%\end{array}$ & $\begin{array}{l}\text { Silent delay/ } \\
\text { Description } \\
40 \%\end{array}$ & 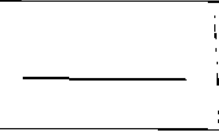 \\
\hline & Unsuccessful & & $\begin{array}{l}\text { Filled pause/ } \\
\text { Description } \\
32 \%\end{array}$ & $\begin{array}{l}\text { Silent delay/ } \\
\text { Description } \\
35 \%\end{array}$ & $\begin{array}{l}\text { Description/ } \\
\text { Filled pause } \\
16 \%\end{array}$ \\
\hline
\end{tabular}

Table 5 illustrates the Ss' performance on the ANT (Obler and Albert, 1986). Level of success for production of the desired lexical item was low for all Ss $-27 \%, 22 \%$ and $30 \%$ for Ss 1,2 and 3 respectively. Results obtained correlate closely with those obtained on the BNT (Kaplan et al. 1976). Ss presented with longer duration when strategies were unsuccessful in facilitating production of the specific lexical item. For all Ss an increase in the number of different initial strategies and strategy sequences was evident when success was not attained. S3, however, deviated from the trend. The number of different initial strategies employed during the BNT (Kaplan et al. 1976) and the ANT (Obler and Albert, 1986 for successful and unsuccessful word searches was equivalent. S1 and S2 employed word-finding strategy sequences while S3 failed to successfully employ strategy se. quences. This is hypothesised to relate to S3's inappropriate both confrontation naming tests and by the studies performed by Pease and Goodglass (1978) and Williams (1983).

\section{e. Summary of results and discussion}

The results indicate that three different patterns of performance were identified with some commonality of wordfinding strategies employed across Ss. The study indicates that a relationship exists between Ss' effective use of wordfinding strategies during procedural discourse tasks and their overall communicative competence, as shown on Prutting's Pragmatic Protocol (Prutting, 1982) and the WAB. Viewed within a compensatory strategy framework, it is advocated that the $\mathrm{CHI}$ Ss are self-monitoring more carefully in an attempt to compensate for their deficits; hence the use of word-finding strategies. This is in accord with Cleary 
(1985) and Teicher $\{1986\}$.

In terms of word-finding difficulty, a confrontation naming task was found to be more difficult for CHI Ss than a procedural discourse task. While procedural discourse maximally challenges the $\mathrm{CHI}$ individual's communicative ability, it may facilitate naming as found in non-brain damaged individuals (Clark and Clark, 1977). The semantic, syntactic and temporal constraints characteristic of procedural discourse \{Ulatowska et al. 1981\} seemed to assist Ss 2 and 3 in the recall and production of the desired lexical items as the "lost" word seemed to be closer to the "tip of the tongue". Within the confrontation naming task, naming of objects (nouns) appeared to be more difficult than the naming of actions |verbs|. This finding is consistent with the findings of Goodglass et al.'s (1966) study and Irvine and Behrmann's (1986) study.

Mean length of response time for successful and unsuccessful searches during the procedural discourse tasks was less than during the confrontation naming condition for all $3 \mathrm{Ss}$. This is hypothesised to relate to the nature of the discourse task which may have facilitated naming. This finding is confirmed by Newcombe et al. 11965, cited by Berko-Gleason, Goodglass, Obler, Greene, Hyde and Weintraub, 1980| and Teicher $\{1986\}$. S1 presented with a longer successful mean latency for object naming versus action naming whereas the converse was found for Ss2 and 3. Furthermore individual patterns exist for unsuccessful mean latencies for object and action naming. It is evident from the data that no one pattern of performance is generated, confirming the notion of heterogeneity within the CHI population (Hagen, 1984; Irvine and Behrmann, 1986). In contrast to this diverse picture, all Ss presented with a longer duration for unsuccessful word-finding strategies during procedural discourse and confrontation naming. Pausing to reconsider and reattempt when not experiencing success is speculated to contribute to this longer duration as CHI Ss experience significant difficulty processing complex information (Hagen, 1984).

All Ss displayed an increase in the number of different in. itial strategies and different strategy sequences when success was not attained. It appears that in an attempt to overcome the unsuccessful attempt, additional and varied strategies are employed. This appears to confirm a breakdown in Luria's 11975$\}$ 'rule of force theory where strong and weak stimuli evoke similar responses so that no selective organisation of the relevant associational process is possible. An analysis of the entire sequence of strategies employed reveals much variability across and within Ss.

The same initial strategies were used successfully and unsuccessfully by all the Ss during the procedural discourse tasks and occasionally during the confrontation naming tasks, namely fluency strategies. This finding correlates with Cleary's (1985) and Teicher's (1986) results. Ulatowska et al. $\{1981\}$ state that in discourse, message transmission in any form is the goal. Therefore the CHI Ss, in an attempt to maintain the conversational flow and transmit the message, predominantly adopted fluency strategies.

Other strategies employed which were not accounted for by Teicher's Behavioural Taxonomy of Word-Finding Strategies $\{1986\}$ were the use of unfinished words, 'Okay', and humour. These strategies have implications in the develop- ment of assessment tools for $\mathrm{CHI}$ and in their treatment.

In summary, word-finding strategies were employed by all the subjects in an attempt to overcome their word-finding difficulty, but to differential effect. There are several possible explanations for the performance variation noted. Coma duration and neurological dynamics may account for the differences. Other variables which may play a role are age range, the time-since-injury and non-medical variables such as personality and motivation since affective disorders are a well-recognised by-product of CHI (Hagen, 1984).

In addition, the increasingly well accepted fact that the $\mathrm{CHI}$ group is a heterogeneous group is a further important consideration. Individual patterns, rather than a single group pattern, characterise this population (Irvine and Behrmann, 1986), a finding supported by this data.

\section{CONCLUSION}

It is clear from this study that CHI Ss are generally using word-finding strategies frequently and effectively to overcome their word-finding difficulties. This is in agreement with the results of Teicher's $\{1986\}$ study.

This may indicate that $\mathrm{CHI}$ Ss are, in fact, effective communicators who learn useful compensatory strategies if given the opportunity to do so [Cleary, 1985; Teicher, 1986). The implications of this finding for remediation are many. In view of the heterogeneity of the $\mathrm{CHI}$ population, it is essential that the clinician assesses each closed head injured patient individually without relying on the predicted findings from the literature. The need for sensitive assessment measures aimed at evaluating communicative efficiency in $\mathrm{CHI}$ is stressed. Measures such as Teicher's Taxonomy (1986) may be employed to present a profile of compensatory strategies. The speech-language pathologist may then structure an effective treatment programme as "... treatment serves to challenge and channel spontaneous recovery, maximise residual function, and compensate for lost abilities." (Hagen, 1984:275.)

\section{REFERENCES}

Annegers, J.F., Grabouw, J.D., Kurland, L.T. and Laws, E.R. The incidence, causes and secural trends of head trauma in Olmsted Country, Minnesota. Neurology, 30, 912-919 1980 .

Benson, D.F. Neurological correlates of anomia. In H. Whitaker and H. Whitaker (Eds.) Studies in Neurolinguistics. New York: Academic Press, 1979.

Berko-Gleason, K., Goodglass, H., Obler, L., Greene, E., Hyde, M.R., and Weintraub, S. Narrative strategies of aphasic and normal speaking subjects. Journal of Speech and Hearing Research, 23, 370-382, 1980.

Brooks, N. Cognitive deficits after head injury. In N. Brooks (Ed.) Closed Head Injury - Psychological, Social and Family Consequences. New York: Oxford University Press, 1984.

Clark, H. and Clark, E. Psychology and Language: An Introduction to Psycholinguistics. New York: Harcourt Brace Jovanovich, 1977.

Cleary, J. Compensatory Strategies in Closed Head Injury. Undergraduate research report, Department of Speech Pathology and Audiology, University of the Witwatersrand, 1985.

Goodglass, H., Kaplan, E., Weintraub, S. and Ackerman, N. The "Tip-of-the-tongue" phenomenon in aphasia. Cortex, 12, $145-153,1976$.

Groher, M. Language and memory disorders following closed head trauma. Journal of Speech and Hearing Research, 20, $212-223,1977$. 
Hagen, C. Language disorders in head trauma. In A. Holland (Ed.) Language Disorders in Adults. San Diego: College-Hill Press, 1984.

IIeilman, K., Safron, A. and Geschwind, N. Closed head trauma and aphasia. Journal of Neurology, Neurosurgery and Psychiatry, 34, 265-269, 1971.

Holland, A. When is aphasia aphasia? The problem of closed head injury. Paper presented at the Clinical Aphasiology Conference, Oshkosh, Wisconsin, 1982.

Irvine, L and Behrmann, $\mathrm{M}$. The communicative and cognitive deficits following closed head injury. South African Journal of Communication Disorders, 33, 49-54, 1986.

Kaplan, E., Goodglass, H. and Weintraub, S. The Boston Naming Test. Unpublished test, Boston, M.A. : Veterans Hospital, 1976.

Kertesz, A. Western Aphasia Battery. London, Ontario, Canada: University of Western Ontario, 1980.

Kirchner, D. and Skarakis-Doyle. E. Dcvelopmental language disorders: a theoretical perspective. In T. Gallagher and $\mathrm{C}$. Prutting (Eds.) Pragmatic Assessment and Intervention Issues in Language. San Diego: College-Hill Press, 1983

Levin, H.S., Benton, A.I. and Grossman, R.G. Neurobehavioural Consequences of Closed Head Injury. New York: Oxford University Press, 1981.

Luria, A.R. Traumatic Aphasia: Its Syndromes, Psychology and Treatment. The Hague: Mouton, 1970.

Luria, A.R. Basic problems of language in the light of psychology and neurolinguistics. In E. Lennenberg and E. Lennenberg (Eds.) Foundations of Language Development. New York: Academic Press, 1975.

Marshall, R.C. Word retrieval of aphasic adults. Journal of Speech and Hearing Disorders, 61, 444-451, 1976.

Milton, S.B., Prutting, C.A. and Binder, G.M. Appraisal of commumicative competence in head injured adults. Paper presented at the Clinical Aphasiology Conference, Seabrook Island, California, 1984.
Obler, L.K. and Albert, M.L. The Action Naming Test, 1986.

Pease, D. and Goodglass, H. The effects of cueing on picture nam ing in aphasia. Cortex, 14, 178-189, 1978.

Penn, C. Compensatory strategics in aphasia: behavioural and neurological correlates. In K.M. Grieve and D. Griesel (Eds.) Neuropsychology. University of South Africa Press, Muckle. neuk, Pretoria, 1985

Penn, C. and Clcary, J. Compensatory strategies in the language of closed head injured patients. Unpublished paper, University of the Witwatersrand, Johannesburg, 1987.

Piaget, J. The Origin of Intelligence in Children. New York: Basic Books, 1952.

Prutting, C.A. Pragmatics as social competence. Journal of Speech and Hearing Disorders. 47, 123-134, 1982.

Russell, W.R. The Traumatic Amnesias. London: Oxford University Press, 1971.

Sarno, M.T. The nature of verbal impairment after closed head injury. Journal of Nervous and Mental Disorders, 1968, $685-692,1980$.

Silverman, S. Research Design in Speech Pathology and Audiology, Engelwood Cliffs, New Jcrsey : Prentice Hall Inc., 1977.

Teicher, S.H. Word-finding Strategies in Closed Head Injured Adults. Masters dissertation, University of California, Santa Barbara, 1986.

Ulatowska, II., North, A., Macaluso-Haynes, S. Production of narrative and procedural discourse in aphasia. Brain and Langauge, 13, 345-371, 1981 .

Williams, S. Factors influencing naming performance in aphasia: A review of the literature. Journal of Communication Disorders, 16, 357-372, 1983.

Ylivisaker, M. and Szekeres, S.F. Managcment of the patient with closed head injury. In R. Chapey (Ed.) Language Intervention Strategy in Adult Aphasia (2nd Ed). Williams and Wilkins, Baltimore: 1986 
APPENDIX 1

Description of Teicher's (1986) taxonomy of word-finding strategies

\begin{tabular}{|c|c|c|}
\hline STRATEGY TYPE & DEFINITION & EXAMPLES \\
\hline ELABORATION & $\begin{array}{l}\text { Expansion or elaboration of the message to ensure effec- } \\
\text { tive transmission. }\end{array}$ & \\
\hline - Description & $\begin{array}{l}\text { Description of the appearance or function of what is being } \\
\text { spoken about. }\end{array}$ & $\begin{array}{l}\text { "I have one at home - it's white and you } \\
\text { dry yourself with it." (Towel) }\end{array}$ \\
\hline - Circumlocution & $\begin{array}{l}\text { Production of general words or "empty words" }\{\text { Heilman } \\
\text { et al. 1971\} in place of the desired word. }\end{array}$ & "You get a free whatschimacallit." \\
\hline - Elimination & $\begin{array}{l}\text { Elimination of a series of words which may be semanti- } \\
\text { cally related to the desired word. }\end{array}$ & "It's not January, it's February." \\
\hline FLUENCY & Used to hold the place in conversation. & \\
\hline - Silent delay & An unfilled pause. & \\
\hline - Filled pause & $\begin{array}{l}\text { Pause filled with some sound indicating ongoing lexical } \\
\text { search. }\end{array}$ & "We use the uh, uhm the book." \\
\hline SOCIAL & $\begin{array}{l}\text { Devices reflecting sensitivity to the needs of the inter- } \\
\text { locuter. }\end{array}$ & \\
\hline - Comment clause & $\begin{array}{l}\text { Any metalanguage about the desired word search used to } \\
\text { maintain a speaking turn. }\end{array}$ & $\begin{array}{l}\text { "You know" or "Oh, what are those } \\
\text { things?" }\end{array}$ \\
\hline - Self-correction & $\begin{array}{l}\text { Correction of phonetic or semantic errors without cues } \\
\text { from the listener. }\end{array}$ & "He hit the bat, I mean the ball." \\
\hline - Requests help & Direct request or a non-verbal cue for help. & $\begin{array}{l}\text { "I'll know if you give me the first } \\
\text { sound", or use of gesture. }\end{array}$ \\
\hline $\begin{array}{l}\text { NON-VERBAL/ } \\
\text { PARALINGUISTIC }\end{array}$ & $\begin{array}{l}\text { Vocal and/or gestural behaviours which supplement or } \\
\text { substitute for the verbal message. }\end{array}$ & \\
\hline Symbolic noise & $\begin{array}{l}\text { Sound effects made in conjunction with or in place of the } \\
\text { intended word to ensure effective transmission. }\end{array}$ & $\begin{array}{l}\text { The use of a high pitched, glottalised } \\
\text { screech made to represent a car's brakes. }\end{array}$ \\
\hline $\begin{array}{l}\text { - Meaningless } \\
\text { gesture }\end{array}$ & Meaningless, natural gesture, lacking structure. & $\begin{array}{l}\text { An upward and outward hand move- } \\
\text { ment. }\end{array}$ \\
\hline $\begin{array}{l}\text { - Iconic gesture/ } \\
\text { Pantomime }\end{array}$ & $\begin{array}{l}\text { Clearly, discernible gesture representing a particular } \\
\text { word, object or its'use. }\end{array}$ & $\begin{array}{l}\text { Left hand in a cupped position as if hold- } \\
\text { ing a jar and the right hand moving in a } \\
\text { circular motion above the left as if open- } \\
\text { ing a jar. }\end{array}$ \\
\hline - Facial expression & $\begin{array}{l}\text { Facial configuration in conjunction with or in place of the } \\
\text { intended lexical item. }\end{array}$ & $\begin{array}{l}\text { Widening of eyes and opening of mouth } \\
\text { to indicate surprise. }\end{array}$ \\
\hline - Deictic & Pointing to an object or in a general direction. & "Over there" or "that one". \\
\hline OTHER & Any behaviour unclassifiable in the preceding taxonomy & \\
\hline $\begin{array}{l}\text { - Incorrect lexical } \\
\text { choice }\end{array}$ & $\begin{array}{l}\text { Synonym or any acceptable alternative for the desired } \\
\text { lexical item. }\end{array}$ & "Digging" for "Pushing". \\
\hline
\end{tabular}




\section{FURNOUIPMEDICAL GROUP}

YOUR YELLOW PAGES OF MEDICAL EQUIPMENT

HEAD OFFICE CORRESPONDENCE ONLY TO: P.O. BOX 84416 GREENSIDE 2034 SOUTH AFRICA TEL. ADD. FURNQUIP TEL: (011) 787-5733/4, 787-5768/9

HEAD OFFICE: "GREENBRIARS" 75 CONRAD DRIVE, BLAIRGOWRIE 2194, SOUTH AFRICA TELEX 4.28072 SA. FAX (2711) 787-5716 ASSOCIATED COMPANIES

Deliveries Store Only c/o Dolphins Transport Joe Arnison Str.

Labore

Brakpan

\author{
Furnquip Medical Natal (Pty) Ltd \\ P.O. Box 1999, \\ Durban 4000 \\ Tel. 031-309-2313/4 \\ Telex 6-22133
}

Furnquip Medical Bophuthatswana (Pty) Ltd

P.O. Box 84416

Greenside 2034

Tel. (011) 787-5717
Transkei Medical Industries (Pty) Ltd

P.O. Box 9030 Madeira Str., Umtata 5100

Tel. 0471-24221

\section{ELECTRONIC ARTIFICIAL LARYNX AND COMPLETE SPEECH THERAPY AIDS}

\section{FQ/:JM001 - Barts Artificial Larynx Mark II}

This has been improved and although an old design, is still very useful as a back-up larynx or as a teaching aid.

$\mathrm{FQ} / \mathrm{JM} 005,006,007,008$

These are the different microphones that are available for use with the De Luxe Speech Amplifier (010) and continue in production unchanged.

\section{FQ/JM010 - De Luxe Speech Amplifier Mk II}

This has been completely redesigned. Output has been increased by approximately one third and a new loudspeaker used which gives a much clearer and more crisp tone.

\section{FQ/JM011 - Mark II Electronic Artificial Larynx}

This unit has been improved and now has a separate ON/OFF isolator switch to prevent accidental use in one's pocket etc. The output is increased and if the optional high power battery is used very great volume can be achieved. This unit is supplied with one battery and charger.

\section{FQ/JM015 - Pausaid}

This is supplied complete with a microphone and battery. Pausaid has a throat microphone which will detect when phonation is continuous and will therefore prompt the patient auditorially to make regular stops in speech.

\section{FQ/JM016 - Vocal Loudness Indicator}

The VLI is a compact battery operated device intended to display relative levels of vocal loudness. The VLI consists of a series of eight numbered lights, each lighting up at a different loudness level.

\section{FQ/JM017 - Companion Intra Oral Larynx}

Introduced early 1987, this has proved extremely successful as an intra-oral larynx for post operative use and in some cases for permanent use by laryngectomies where a throat larynx is not liked or acceptable.

\section{FQ/JM018 - Summit Amplifier}

This is an amplifier in the same housing as the Mark II 010 amplifier.

\section{FQ/JM019}

Headset or throat microphone for the new type amplifier 018.

\section{FQ̈/JM020 - Pocket Audiometer}

This unit is designed as a front line free field screening audiometer capable of quickly and easily checking whether or not a patient has a hearing problem.
For further information please fill in the following and return:

Surname:

First Names:

Address: 